\title{
Virtual life: self and identity redefined in the new media age
}

\author{
Teresa Wennberg \\ The Royal Institute of Technology, Sweden \\ teresa@pdc.kth.se
}

\begin{abstract}
In this article, the author discusses her virtual reality installation The Parallel Dimension and goes on to explore the conflicts of identity experienced when a person is confronted with VR as a total immersion. She suggests that the various questions arising through this experience may lead us to a more ambivalent concept of the self.
\end{abstract}

Keywords: CAVE, identity, immersion, reality, virtual reality
I fell asleep and dreamt that I wasa butterfly. Now I no longer know if I am Chuang-Tze dreaming that he is a butterfly or if I am a butterfly dreaming that he is Chuang-Tze.

(Chuang-Tze)

In January 1998 I was invited to the Centre for Parallel Computers at the Royal Institute of Technology in Stockholm (KTH) to create a Virtual Reality artwork for a so-called 'CAVE'1. The final result, theVR installation The Parallel D imension, was presented to the public during D ecember 1998.

The $\mathrm{C}$ entre for Parallel Computers is the Swedish centre for scientific calculations. It has an important supercomputing network, which is among the most powerful in Scandinavia.

The CAVE at KTH - or 'VR Cube' as we call it - is a 'total' VR installation. All sides, including the ceiling and the floor are projection screens. Large video canons project the images from all sides through back projections and with the help of mirrors. This means that the projected images are not disturbed by the shadows of the visitors, permitting a complete immersion in virtual space.

The images are projected in stereo to enhance the impression of depth. Each visitor wears LCD shutter glasses, which allow a view in 3D (each eye sees only one of the two perspectives). Glasses with special tracking sensors, as well as a pointing device or a glove are given to one of the visitors (Figure 1).

In order to navigate in the VR Cube, one person must wear the special glasses which hand over the direct tracking information to a separate computer. This computer's only occupation is to calculate the $x-y-z$ parameters 
in virtual space, thereby constantly updating the position of this person in real time and of the projected images.

If there are several people at once in the Cube, those carrying 'normal' glasses get a slightly divergent point of view (hardly noticeable).

The construction measures $3 \times 3 \times 2.5$ metres, accommodating up to nine people simultaneously, and thus opening up the possibility for a simultan eous collective experience. In order to allow back projection onto the floor, the floor was raised 2.5 metres to provide space for projectors and mirrors. The floor is made of $40 \mathrm{~mm}$-thick acrylic glass and this glass is covered with the same fabric for projections as the walls and ceiling. 0 ne of the Cube's walls serves also as a large door, which is hinged on the outside and swings open to allow access to the room.

The system is run by a special graphic computer: a Silicon Graphics 0 nyx2 with twelve CPU s and $4 \mathrm{~Gb}$ of memory, $100 \mathrm{~Gb}$ hard disk and three InfiniteR eality2 graphic pipes with two $64 \mathrm{M} \mathrm{b}$ raster managers each. Each pipe manages two of the six surfaces.

The floor and ceiling are currently configured to run with a resolution of $1024 \mathrm{x}$ 1024 pixels at a frequency of $96 \mathrm{H} z$. The walls run at $1024 \times 852$ pixels to keep the pixels square and to keep the resolution constant along the edges.

$M$ any steps and phases are involved in creating a VR piece: technological innovation is a costly and complicated activity. Each discovery is preceded by a long process of trial and error. It is also an intellectual challenge to confront this new 'reality'. For me, as an artist, the most exciting aspect is the conceptual confusion with which VR confronts me. The total immersion in a virtually real environment has led to a number of unknown sensations, out of which many questions arise. It has given birth to a stimulating play of thoughts where the identity of self needs to be redefined.
In my VR piece, The Parallel Dimension, I concentrated on creating forms which look realistic while challenging our current way of relating to the conventional language of form. For this, I used sophisticated texture maps and unexpected constellations of forms or often perspectives of gigantic space (Figure 2). My artistic intention is always to stretch our concepts of reality. It is a challenge to create situations which, for example, seem to abolish the law of gravity yet look completely natural.

The Parallel Dimension is a metaphor for the human body, where every world represents an imaginary part, filled with strange forms, textures and light effects. I have especially worked with the idea of movement, particularly important in a virtual environment. I want the presentation of this work to be seen as a prolongation of the moving art forms, where the motion itself is an important expression of the artistic intention. Here the movement is threedimensional and we can change the aspect of the forms and of the worlds at every moment and also go forwards and backwards in time. Thus the work is in constant transformation, which is the first step towards a new form of interaction.

The first and most important thing when we speak about virtual reality is the fact that we are no longer spectators in front of a screen, we enter the virtual world as Alice stepped through the looking-glass. We are no longer sitting passively in front of an alienating glass wall, we are standing up or moving and taking part in the action. I mage has suddenly become space and we can move around in what we see.

We can approach all the objects as we please, turn around them, even put our head through their seemingly impenetrable surfaces and see what's inside. We can move around freely in this space: go forwards, backwards, change pace, stop, start again. We are moving in a situation which is adapting itself in real time.

We stand in a room which isn't a room but more like a gateway, where the visible 


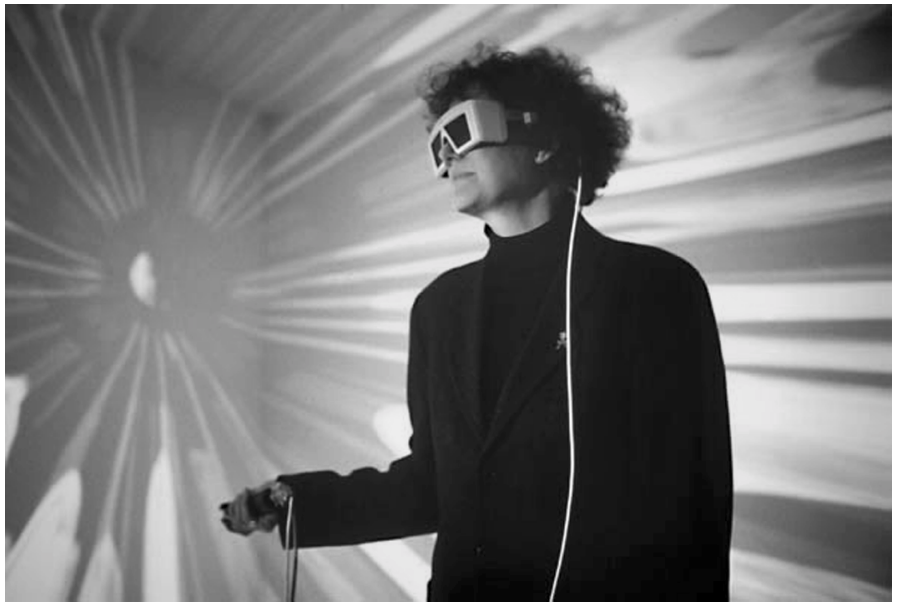

Figure 1. The author in the VR Cube wearing the 'leader glasses' and holding a manual tracking device.

( Image b y courtesy of the author) boundaries are illusory. The physical limitation of the walls of the cube are soon forgotten as we are introduced to this other space. The rectangular shapes of the room dissolve into vast cathedrals or faraway horizons. D istance appears as in the real world, with the same relation to perspective: when things are far away they seem smaller. A small point at the far end in a space is thus experienced as actually being very far away - and physically it also takes a certain time to reach that point.

Our visit to The Parallel

Dimension begins in a big, ochre-coloured oval room. The walls are covered with old-fashioned black-andwhite pictures of the brain. This is The Brain Chamber, the central location, from which every move is directed. At each cardinal point, an animated screen is seen. If we come too close, it will absorb us and hurl us off to one of the parts of this virtual body. We travel like little particles through thin twisting 'veins' to the different locations: The Heart \& Blood Room, The Thought Cabinet, The Breathing Cathedral, The Flesh Labyrinth, and through a secret passageway down to The Dream
Cavern. Every world has an exit - visible or hidden - that the visitor must find in order to return to The Brain Chamber.

The brain is the centre of our body, where information about the surrounding situation is received, synthesised, and revised. Is the situation safe, or is it dangerous? C an we relax, or should we be on guard? Is it day or night? H ow is the weather, the temperature?

In a 'normal' situation the brain processes all this information, ignoring some signals, paying attention to others, reaching a conclusion and making decisions about behaviour and actions. In general, the input is processed in a relatively calm and orderly manner. We have learned to behave rather well and to plan our needs in advance.

When we find ourselves in an unexpected situation, however, glands swell, adrenaline floats. We are more alert and concentrated. If the situation really seems out of control, still other aspects take over. We may react violently, sometimes even losing control over our actions, making false moves, wrong decisions. We easily go back to more primitive behaviour with uncontrolled outbursts of fear and anger.

When we enter the VR Cube and are confronted with a virtual experience, we can establish that, from a physical point of view, we are still attached to earth. 0 ur brain subconsciously registers that our feet are placed on solid ground, the pressure on the skeleton and muscle fibres feels 'normal' and the body weight is distributed like it usually is. If asked how our limbs are placed, we would probably answer, "I am standing up".

At the same time other parts of the body - eyes, ears and subsequently nerves and muscles in the head, neck and back - are bombarded with information about a different 
situation, for example: "I am flying at high speed, at high altitude, over an unknown territory". This message is stronger than the message telling us that we are standing on the floor. The eyes win out over the extremities. We believe more in the information that our eyes are sending us than in the information from the nerve endings in our feet.

The brain cannot combine these diametrically opposed signals. And so it is confused and our co-ordination falters. We can compare this experience to the feeling generated by a sensory deprivation tank, where the body is afloat in a salt solution, which rapidly makes one lose contact with one's extremities. There are no visual stimuli. The brain becomes a floating, humming centre, an isolated reception unit for the feeble and confused information that comes from our limbs. This is also a 'separate reality' where the brain is fooled. A pparently the brain is easy to mislead. Is virtual reality more like a waking dream for the brain than a 'true' reality? In fact, we do find ourselves in a state that can be compared to that of a dream: we can fall, but do not hurt ourselves, we can advance with great speed but are nevertheless standing still. Contact with the 'known' world is broken in as much as we accept our presence in this new world. Of course, we can end the experience at any moment, open the door and return to our 'true' reality, but as long as we are in the Cube we accept the information given as valid. And the illusion is perfect: horizontality/verticality, depth/closeness, hardness/softness, transparency/opacity, surfaces, colours, light effects... all exterior attributes of the forms look right according to our customary visual norms.

Through the animated screen for The Heart \& Blood Room we are sucked into a virtual vein and conducted in high speed to a completely red room. Blood is dripping and running on the walls. In the middle, an amorphous mass is laboriously moving, twitching, moaning. There is a throbbing sound. One is startled, curious, a little disgusted perhaps.

From The Heart \& Blood Room, we travel back to The Brain Chamber by penetrating this metaphor for a pumping heart.

It is an interesting mental exercise to try to define this spatial confusion. Which reality is the true one? (W hat is 'truth'?) D oes it depend on physics, or on what I experience with my senses?

0 bviously, nerves don't 'think', they transmit. The eyes relay information about light waves and frequencies that the brain has laboriously learned to analyse and interpret in a special way. Exactly how it transforms these signals into images is a complex procedure that has yet to be explained.

But what is really interesting in the $V R$ Cube is that when we are given two sensory inputs - "I am standing up" versus "I am flying" - the false one seems more real than the true one. The brain is simply not as clever as we like to believe.

In his notebook, Zettel, W ittgenstein asks:

$\mathrm{H}$ ow would it be if somebody seriously told me that he (really) doesn't know whether heis dreaming or he is awake?

Can this situation exist: Somebody says "I think I am dreaming now"; in fact he wakes up just after this, remembers this uttering from his dream and says: "So I was right!"

Imagine an unconscious person saying (for example under anaesthetics) "I am conscious" would we say "he should know that"?

And if somebody in his dream would say "I am seeping", would we say "H e is perfectly right"?

Isa person lying if he says to me: "I am not conscious"? (And ishe telling the truth if he says this being unconscious?) (Wittgenstein 1967 85)

In The Breathing Cathedral we fly into an enormous ... cathedral? ... spaceship? ... world?

A star-filled galaxy, with a great number of 


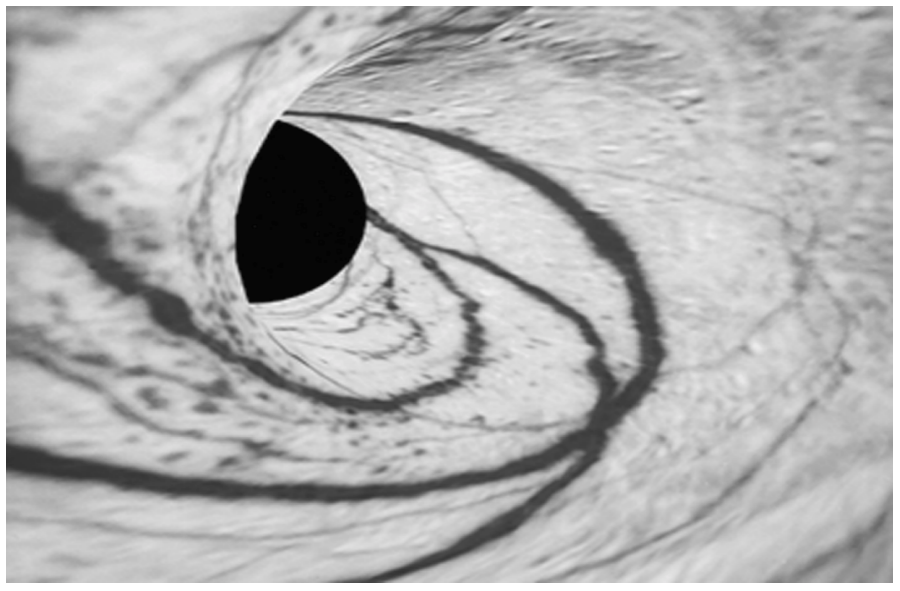

Figure 2.

View from the VR installation The Parallel Dimension' (1998)

by Teresa Wennberg. This image depicts a movement between The Brain Chamber' and The Thought Cabinet'. We are travelling at high speed inside a virtual nerve. multicoloured semi-transparent spheres of varying size, gives an overwhelming sensation of infinite space. A sound is heard, difficult to define, but rather pleasant and well-suited to this strong impression of immensity. (Many visitors claimed having a metaphysical or 'near-death' experience when moving softly through this calm and immense world.) We float in space ... or in the womb. A mixed feeling of freedom and apprehension as we advance majestically among the multitude of distant lights and passing transparent planets.

In the far end of this space, an eye-like shape appears. As we approach, the 'retina' turns out to be a narrow cone-like corridor through which we are squeezed into the centre and then swirled back to The Brain Chamber.

To go a bit further with this discussion, we can attempt to separate our concept of reality into different layers.

To begin with, there is the 'objective reality', which K ant referred to as D as D ing an Sich (the thing itself ). This is the reality behind our reality, a realm which we cannot observe, where the objects might live their own life. This reality exists beyond the human capacity to measure in terms of time or space. We can know nothing about this reality, we can only suppose that it exists.

Then we have the 'known reality', the so- called measurable reality. It is the reality we relate to in our everyday life and nevertheless hardly ever define. Here a chair is simply a chair, with no deviations to bring the matter into dispute. A generalised and superficial use of the language is sufficient for referring to the objects. 0 ur daily life is based on relative assumptions about time, space and the objects in them. In order to live in any community, we need to subscribe to a great number of common expressions which we cannot constantly question, even if they often are based upon vague or even false references. A complex system of relativisation, used by all our fellow humans, creates the symbols we need on a daily basis. Everything has (and must have) a name, even if we question its meaning at times.

And now this new state, this new reality, this magic room where objects, though looking familiar, have yet another character. This room is closed but endless, and time exists far beyond the scanty restriction imposed by a watch. It's like entering a giant brain (Figure 3 ). VR is a mind expander. It confronts us with an extra dimension, that really exists. And here is the hook. In an instant, reality turns multiple, transcendental, vertical, non linear. We could be approaching a new philosophy of perception and of life: the relation to 0 ne could break up and thus a fundamental foundation of Western religion. Back to multiple gods?

In The Thought Cabinet we enter what at first seems to be a colourful forest. The trees look as high as the giant seqouias of Northern California. Soon we realise that these trees are in fact gigantic letters forming words and phrases. They are placed in such a way that we can wander between them, beside them, even walk right through them. Again, this sensation of being very small in a gigantic space affects the spectator, who soon discovers that the phrases are fragments from the famous monologue of Hamlet.

A soft voice reads the sentences with a humming sound. The exit is a golden arch at 
the opposite end of the room.

Time is an important basis of our mode of perception. Einstein taught us that time is relative, depending on where we are and how we measure. It is also very personal: one minute is a short unit, but a minute can subjectively seem like an eternity. D epending on the amount of sense data we receive during sixty seconds, our experience of this period can be totally transformed.

When we find ourselves in a new environment, information intake is multiplied and our attention is at a high level (especially since we have a tendency to compare everything to our known world and search for our prefabricated definitions). In a situation where the body produces extra adrenaline and our senses are in peak performance, brain activity is much greater than it is when dealing with a familiar situation. We lose our normal apprehension of time passing'. This diverts our concept of reality and again time appears to be an elastic variable.

The difficulty in giving a correct analysis of this experience can be seen as a reflection of the difficulties in finding the language to explain what we are apprehending. $\mathrm{H}$ aving the meaning before our minds is by no means a guarantee for being able to explain anything.

$\mathrm{H}$ ere is where the conceptual crisis begins: I know that I am standing in a projection room and that the images and forms which are projected in the room are betraying my senses. I know that this is a virtual material and I know that it is created by a computer, thus is not what we can call 'concrete' reality. I know that I can turn off these images and go back to the other existence.

'I' am not fooled. But perhaps my brain is. Is that the same thing? Is my brain playing a game with me? Am I the one who is changing? Who am I?

This is an interesting question to pursue: what is the 'I'?

This question has been treated by most of the great thinkers. Perhaps D avid H ume comes the closest to an up-to-date interpretation when he claims that the ' $I$ ' is a long string of experiences - a great number of different apprehensions following one another with inconceivable speed, constantly changing and constantly in motion. Like a Buddhist, $\mathrm{H}$ ume sees consciousness as a kind of theatre, where impressions appear and mix with each other into an endless multitude of positions. We have no underlying 'personality' behind these moods that come and go - we are movement ( $\mathrm{H}$ ume 1962).

\section{Flusser:}

Similar thoughts are also evoked by

That what wecall 'I' is a knot of relations, which, when unpeeled, revealsitself to have no hook on which these relations may hang...

(Flusser 1994)

In virtual reality, common sense may doubt part of the information, but some of the most important physical means we possess for collecting information from the exterior world are totally fooled. Shall we write off all this information as mental chimeras and sophisticated brain ghosts? M aybe, but 'I' believe them.

In the words of Lucas M anovich:

Throughout human history, representational technologies have served two functions: to deceive the viewer and to enable action, i.e. to allow the viewer to manipulate reality through representations.

(M anovich 1997)

Jean Baudrillard suggests that mass media operate in a manner contrary to the way they present themselves: they do not inform, they impose. They give out information, but people cannot respond. It is a non communication, an ongoing soliloquy which puts us in a state of insecurity concerning our personal choice.

$\mathrm{N}$ evertheless, the contemporary citizen bases most of his visions of the surrounding world and its matters on televised images. Since television entered our homes in the 1950s, we have become visual slaves to its message: seeing 


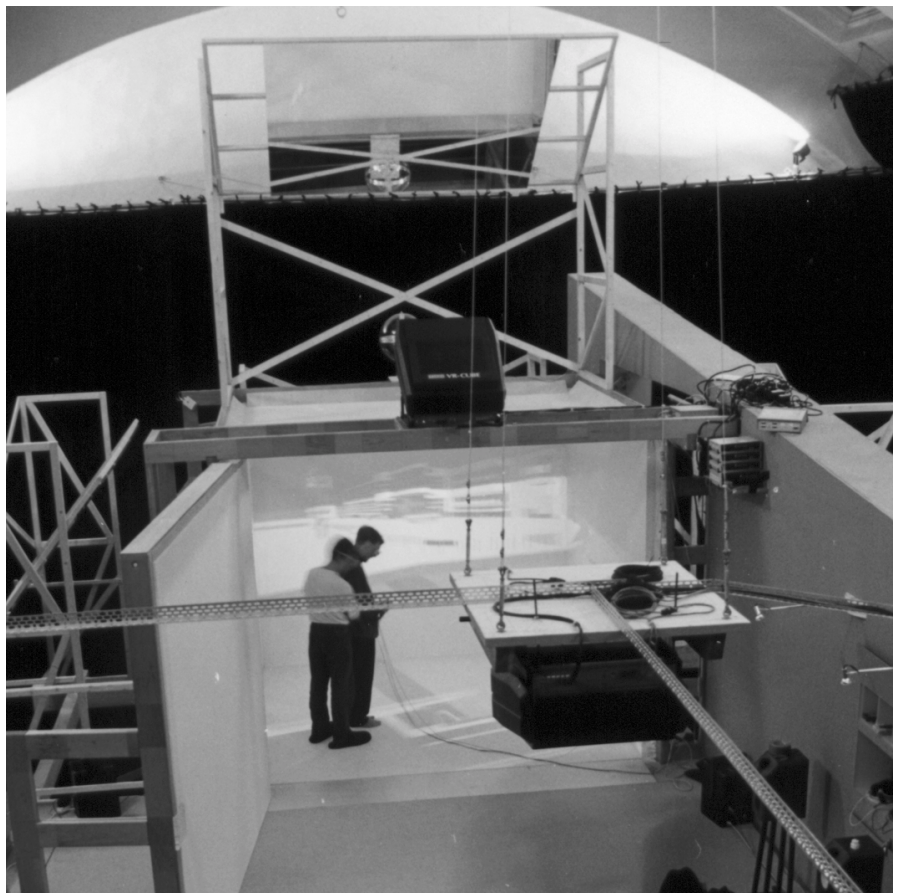

Figure 3. Birds-eye view of the VR Cube at The Royal Institute of Technology, Stockholm. This construction, which uses all four w alls plus the ceiling and floor as projection screens, is the first in the w orld to permit total immersion. is believing. W hen we turn on the evening news, we see electronic images of something that is happening far away from home, maybe on the other side of the planet. The truly fascinating thing is that television has created an absolute credibility with the concept of 'live' transmission - that the situation is going on simultaneously in the TV studio or on the war field. But if we really think about it, there is nothing whatsoever proving to us that it is neither 'live' nor 'true'. We just see a lot of images on a screen. What is revolutionary is that so many people are looking at these images simultaneously and talking about them as being part of a collective truth (which could be considered a collective hallucination). It is as easy to manipulate an image as it is to create one. But television has acquired such credibility that we accept the information it offers without questions. W ill VR affect us the same way once it becomes an everyday experience?

The Flesh Labyrinth takes us to a con- struction of pinkish membranes as high as a three-floor building where we move mostly vertically. Virtual pieces of flesh obstruct the passage; the sound when touching them suggests a blow. This is a slightly claustrophobic experience. How do we get out? Find the hidden exit which is encapsulated in a blue ball, coyly avoiding an encounter...

So how come we are aware of the virtuality of these realistic visions and yet react as if they were really part of our external world? We are exposed to an increasing intrusion into all areas of life of the uncertainty and unreliability of the real, with an increasing difficulty to determine where to put the lath. The Swedish philosopher Gunnar Svensson goes even further:

Is there really an external world? T he question may seem rather silly at first. The sceptic, however, asks for a justification of something we are all sometimes deceived by, viz. our sense experience. What guarantees that it is not always delusory? Common sense? L ogic? God? Clearly, there is no obvi ous answer. D oubting the existence of an external world does not seem so silly after all. Why, indeed, accept that there is one?

(Svensson 1981)

$$
\text { Or, as G.E. M oore put it: }
$$

In order to prove my premises I should need to prove one thing, as D escartes pointed out, that I am not now dreaming. But how can I prove I am not? I have, no doubt, conclusive reasons for asserting that I am not now dreaming; I have conclusive evidence that I am awake; but this is a very different thing from being able to prove it. (M oore 1953 149)

Perhaps the answer is that there are different levels of consciousness and different forms of the 'I', which all make up a part of what we would call our personality and our reality. $\mathrm{H}$ ere we have the well-polished surface, the secret thoughts and the repressed instincts, the thief and the sex maniac, the liar and the flatterer, some kept down, some brought forward. But these various qualities all spring 
from the same brain.

We could think of our brain as a vessel receiving a constant information flow. The 'I' could be seen as the recollection of this information, depending on our individual memory. 'Reality' is the interpretation we give to this information at every moment.

If then the brain decides with a majority of neural votes that we are flying - in spite of the fact that we are not - is it then so? Apparently we can no longer trust our classic brainbody-spirit concept. We are facing a major cognitive shift, where we will have to introduce a new way of conceiving our world, admitting that a double reality - or several simultaneous realities - can exist and be accepted as valid. 0 ur bodily functions will not change, but our consciousness will.

Having tried all four visible doors, we're back again in The Brain Chamber.

The final visit is executed through the semi-transparent pillar in the middle of the room. One must discover this oneself; there is no exterior indication of it. But once we get the idea to penetrate the pillar, we are taken by an invisible elevator down to the last world: The Dream Cavern.

Dreams are images, sounds and strange sensations that bring us back and forth in our subconscious memory. Here, the images come sailing through the winding cave and the walls are made of more images, images everywhere and voices whispering mysteriously. Written messages float in the air. We read the word 'KEEP', which is almost invisible, then turn around another bend and read 'YOUR ILLUSIONS' ....

At one point in this hallucinatory but fascinating universe we see a burning circle, like the ones felines jump through in the circus. Inside the flames the word 'JUMP' is written. Of course we jump. And we return to The Brain Chamber.

Two simultaneous realities? O ne plus one equals one? Which life, which reality will eventually be referred to as the 'true' one? And - does it matter?

$O$ ver the past generation, virtual avatars of ourselves have multiplied ceaselessly. In the financial world there is a constant exchange of virtual money at the same time as film and photographic art portray scenes that never took place between people who never met. M U D s and similar worlds on the Internet are just one aspect of a metaculture which encourages different models, personalities and roles. $\mathrm{H}$ undreds of thousands of people are creating virtual personas, living in groups of virtual societies with multiple identities, undermining the $C$ artesian idea of the unique subject.

The computer and the television have become machines of reproduction instead of production. 0 ur culture is tainted by the appearance of a new absence of depth, by superficiality in the most literal sense of the word. We are experiencing the dissolution of the individual and a decentralisation of the subject - and the object.

In a very short lapse of time, Scandinavian cyberlife has increased incredibly. Sweden is a forerunner in the use of advanced electronic media, mobile phones, personal computers, and public use of the N et. Surfing is highly encouraged. In fact, Swedish daily life is more and more depending on computerised services. There are very few companies who do not work with computers in one way or another. We can order pizzas and do all sorts of bank errands, pay our bills, study all the way up to a $\mathrm{PhD}$, make legally valid orders and, of course, correspond by email with our friends and colleagues. The art of writing letters by hand is becoming obsolete and the Swedish post office is eliminating more of its customary services every month.

Anders $\mathrm{H}$ ector, research scientist at the Institution for Technology and Social Change at the University of Linkoping is working on a thesis about information habits. In a recent article, he mentions an American study which found that the risk of loneliness and depression is increased if one surfs on the $\mathrm{N}$ et for even just one hour per day. 
H ector says:

Life in cyberspace is after all abstract and reality is concrete. The $\mathrm{N}$ et does not offer the same width of interaction with smells, tastes and feelings. To surf on the Internet does not give the same feeling of social repletion as physical encounters between people.

(H ector 1998 11)

Of course, $\mathrm{H}$ ector is referring to a situation which, in nine cases out of ten, means accessing a two-dimensional Internet service on a small home computer. The impenetrable screen mirrors a communication, but is not really communicating. This is why the possibility of interfering with the forms, or affecting a given situation, is perhaps the most important part of a VR experience and where most of the research and development are focusing.

In this new reality, we are not only immersed, but we can interact with it - we are real-time actors and the role we play is that of a decision maker, a secondary creator. D epending on the programming - which will soon include the possibility of travelling within the $\mathrm{N}$ et we can intervene in the scenario and change it to better suit our needs or wishes. We can move existing objects, add new ones, we can meet with and talk to others although they are not in the same room. In fact, we can totally change a given situation in a matter of seconds. This is a major change from passively onlooking at a closed scenario and it is perhaps the most revolutionary shift in computer-based communication. In the VR Cube, there is also the simultaneous collective and physical sharing of an experience (which has nothing to do with looking at the eight o'clock news).

But also here we confront a lot of intricate questions. When I place a secondary 'me' in a virtual board meeting - an alias representing my body and my opinions - who is the person moving in this new room? Is it my usual me? Have I divided myself into two? Is it a 'mental clone'? Is it all of me? To what degree is it responsible for its actions? Are its actions to be considered mine?

If my alias signs a contract - is it valid? Can somebody else direct this avatar of mine? W ill we face different degrees of existence, one absolute and others more relative, with various degrees of personal responsibility? $0 f$ course, it is nothing new to have a personal representative or substitute. W hat could be intricate is if and when these aliases become autonomous and start making decisions on their own.

We will certainly have to invent new definitions of legal and moral order.

Virtual space is about to transcend the capacity of the human body to localise itself, to perceptively organise its surrounding and to produce a cognitive map of its position in a recognisable, outer world. We will rely more and more on electronic communication, which also means that we will be more vulnerable in case of a breakdown. If the line is disconnected, we will be lost and retarded. And perhaps without memory. The ultimate amnesia.

But even this may just be a small point. The main criticism of three-dimensional virtual reality could in fact be its lack of physical touch, of flesh and blood or solid matter, so fundamental to us human beings. This lack could indeed contribute to the aforementioned feeling of emptiness in cyberspace. Even with the data glove we cannot really touch the forms, however visually convincing they may be. We can travel, act and inform ourselves, but as long as there is 
no real physical encounter there will eventually be a feeling of unfulfillment due to the ephemeral quality of the experience.

Touch - is that the final step between the virtual and the physical world? Both M ichelangelo's portrayal of God and Adam in the Sistine Chapel and Spielberg's film ET, where a divine finger reaches out to the mortal human, offers us a metaphor for the importance of physical touch. M ost encounters, chats and business deals on the $\mathrm{N}$ et either end up with a personal rendezvous at some point - or whither. People like to meet physically, to look at each other face to face, to shake real hands and feel, sense and smell each other. It is a fundamental need for us to be with other people, it is part of our genetic heritage. So, how do we solve this problem? Either we invent a new definition of the idea of 'touching' or we manage to create virtual substitutes that are as impressive as the visual and auditory information is now. The most interesting thing now is to see what kind of avatars we can come up with.

$C$ an we manage to create virtual substitutes as impressive as a human being? Like in Gibson's I doru, where the hero falls in love with a virtual girl, who only exists inside the computer (Gibson 1996).

$M y$ tip is that we will become so alienated from this harsh reality that we will eventually prefer the ephemeral company of virtual creatures and the timeless pleasure of virtual lives. Touch is a sensual experience, on a par with seeing but communicating with other centres in our brain. So far the computer experience is mainly a visual one. Will seeing overtake touching? Can we become so dependent on our eyes that other senses are reduced to a secondary position?

Time will show.

\section{Notes}

1 'CAVE Automatic Virtual Environment', a technique for projecting three-dimensional pictures on several walls of a room, originally developed by Carolina Cruz-N eira and Tom D eFanti at the University of Illinois in Chicago.

\section{References}

Baudrillard, J. (1995) The Gulf War did not take place. Trans. Patton, P. Power Publications, Sydney.

Flusser, V. (1994) O n memory (electronic or otherwise). Art/Cognition. Cyprès/Ecole d'Art d'Aix-en-Provence.

Gibson, W. (1996) I doru. N orstedts Förlag, Stockholm.

H ector, A. (1998) Svenska D agbladet 19.9.1998, p. 11.

H ume, D. (1962) A treatise of human nature. Book one. William Collins, Glasgow.

M anovich, L. (1997) To lie and to act: Potemkin's villages, cinema and telepresence. ISEA 97.

M oore, G.E. (1953) Proof of an external world. In M oore, G.E. Philosophical papers, George Allen and Unwin, London.

Svensson, G . (1981) On doubting the reality of reality. Almquist \& W iksell International, Stockholm.

W ittgenstein, L. (1967) Zettel. Trans. Anscombe, G . and von Wright, G. Blackwell, Oxford.

Teresa Wennberg is a visual artist, working with painting, video and computer animation. Her installations combining all of the above has been shown in galleries and museums throughout the world. Since 1998, she has been attached to The Royal Institute of Technology (KTH).

Web site: http://www.nada.kth.se/ -teresa 